\title{
Secretory Cell
}

National Cancer Institute

\section{Source}

National Cancer Institute. Secretory Cell. NCI Thesaurus. Code C13055.

One of several types of cells that generate and secrete a substance to be used by the organism. 